\title{
Car Engine Oil: Investigation of Function and Related Challenges, and Provision of Environmental Solutions
}

\author{
Atefeh Hasan-Zadeh ${ }^{1}$ and Mohammad Poshtiban ${ }^{2}$ \\ ${ }^{1,2}$ Fouman Faculty of Engineering, College of Engineering \\ University of Tehran, Iran \\ ${ }^{I}$ Email: hasanzadeh.a [AT] ut.ac.ir \\ ${ }^{2}$ Email: poshtiban.mohamm [AT] ut.ac.ir
}

\begin{abstract}
In this paper, in order to solve challenges in the field of energy and fuel using a fully practical approach, types of engine oils and advantages of each over the other are discussed. A suitable car engine oil and its reasons are addressed. The viscosity of the engine oil is studied. A suitable car engine oil for cold and tropical regions of Iran is introduced. The standard classification of engine and gear oils in terms of viscosity is another topic discussed in this paper. Burning oil of Iranian cars, its reasons, identification methods and reduction strategies in accordance with domestic standards are described. Finally, plant-based engine oils, their applications, advantages and disadvantages, native challenges in this field and its complementary topics of the environmental aspect are provided in the present study.
\end{abstract}

Keywords - Engine oil, Viscosity, Burning oil, Plant-based oil, Lubrication

\section{INTRODUCTION}

Engine oil, which plays the role of blood in the arteries of the engine, is produced from compounds such as base oil and additives. First, it is produced from crude oil in the refinery and then it is sent to the extraction unit as the raw material of lubrication unit, where the substances that contain gasoline compounds are removed. Raffinate (refining material) containing the oil is then sent to dewaxing unit to separate paraffin and wax, and finally to furfural unit to produce the petroleum-based oil.

Engine oil has two main functions in car engines as follows:

1. Lubrication

2. Cleaning

Depending on the type of engine in terms of power and production speed, as well as alloys used in parts such as pistons, cylinders, valves or special rubber parts such as radial shaft seals, washers, bearings, and etc., suitable engine oil can lubricate and clean as correctly as possible. This engine oil is specified by the car manufacturer in the car manual. For example, a suitable engine oil for Pride is fully explained in the car's manual.

Engine oil has many applications as follows:

1. Minimizing friction and wear between car engine parts

2. Absorbing pollution and sediment sludge from the operation and combustion of the engine and keeping the parts inside the engine clean.

3. Reducing the heat generated by the engine function and cools the engine.

4. Smoothing the movement of the parts by sealing the parts.

Therefore, suitable additives should be used to produce such oil.

In this paper, types of engine oils and the advantages of each over the other are discussed. Engine oil suitable for the car, its reasons, and the viscosity of it is discussed. The suitable engine oils are introduced for cold and tropical regions. The standard classification of engine and gear oils in terms of viscosity is another topic discussed in this paper. The manuscript describes burning oil, its causes, identification methods, and reduction strategies, too. Finally, it has been addressed plant-based engine oils, their applications, advantages and disadvantages, and its complementary topics of the environmental aspect in the present study. 


\section{TYPES OF ENGINE OILS}

The contents of this section are mainly adapted from the systems of reputable and related companies and some indigenous research, [1].

Engine oil can be divided into five groups:

1. Mineral-based oils

2. Synthetic oils

3. Mineral and synthetic-based oils (semi-synthetic)

4. Oils from mineral base optimization (new generation base)

5. Refined base oils (mono-grid)

Learn more about them now:

Mineral: It is a type of oil that is produced from crude oil and is a common oil that is used in all cars. This type of engine oil has long been used in cars.

Synthetic: It is an oil that is produced using chemical compounds or polymerizing hydrocarbons (olefins). This oil was used only for jet engines, which due to the advancement of technology, it has been possible to make it for cars. This oil has many advantages over the mineral type and it should be noted that this product is still more expensive than the (normal) mineral type.

Also, this oil is not compatible with old cars and it is better to consult a specialist before using it in old cars. There are different types of synthetic oils with different ingredients. Among types of synthetic oils with different formulas, each of which has its advantages and disadvantages, the type that is made on the basis of polyalphaolefins (PAO), has the highest efficiency and acceptance. This type of engine oil also has less ester.

Advantages of synthetic engine oils over conventional oils are as the following:

1. Longer life than conventional engine oil

2. Less corrosion and non-toxic

3. Less evaporation than conventional type

4. High burning temperature

5. High oxidation resistance

6. High viscosity index naturally (rapid reaction to temperature changes)

7. Reduce fuel use by $4.2 \%$

8. Low lubrication point

Semi-synthetic: This engine oil, as its name implies, is a product between mineral and synthetic types i.e. this product has some features of the synthetic type and some features of the conventional type. The general recommendation of experts is that this product should not be used for very old cars. The use of this type of oil for very old cars due to its structure causes damaging pistons and as a result, the engine will fail.

The quality of this type of oil is higher than mineral type and at higher temperatures it shows better function than mineral type and has a higher price than it.

Basis of the new generation: This type of oil is used for production of new oils and is similar to mineral-based oils from petroleum-based oils.

Refining-bases oils (mono-grid): This oil is used for production of low-level oils and due to its acidity, it is extremely harmful to the car engine and it is recommended to avoid using it.

Engine oil for high-function cars: This engine oil is suitable for engines that are old or have operated for more than 100,000 kilometers. The additives to these oils prevent the car from burning oil. It also prevents oil from leaking into combustion unit of the engine. It should be noted that in this case, before choosing the oil, be sure to read the manual related to the car.

Following these points will extend the life of your engine oil:

1. Avoid combining several engine oils 
2. After turning on the car, let it run for 15 seconds

3. Each time you change the oil, change the filter.

4. Do not use additives as it may not be compatible with your oil

5. Check the date of the oil and do not use oil that is more than three years

6. If you have been using mineral oil for many years, do not replace it with synthetic or semi-synthetic oils.

\section{ENGINE OIL SUITABLE FOR CARS}

The contents of this section are mainly adapted from some domestic research and the systems of reputable and related companies, [2].

There are many choices, options and criteria to choose the right oil for your car engine. In order to choose engine oil, we should pay attention to two categories:

1. In terms of viscosity (SAE)

2. In terms of quality (API)

The concentration should be selected according to the car manual, so this amount is completely specific. But when it comes to engine oil quality, we need to look at what affects engine oil quality. The additives to engine oil have the greatest effect on the quality of this product and materials that prevent stain, corrosion, temperature increase and friction of the car engine.

Therefore, care should be taken in choosing engine oil based on quality and concentration under different climatic conditions. Table 1 (which follows) will identify the quality classification and the description of the oil concentration (viscosity). In general, it should be noted that in tropical weather, oil with high viscosity and in cold weather, low viscosity should be used. As a result, if high viscosity engine oil is used, it will not be lubricated in cold weather and will damage engine parts.

\section{ENGINE OIL VISCOSITY}

The contents of this section are mainly adapted from the systems of reputable and related companies, and some publications, [3-5].

Viscosity (concentration) is the degree of resistance that a liquid has to flow. As a result, the higher the viscosity of the oil, the more condense the engine oil. For engine oil, this concentration is investigated at zero degrees Fahrenheit (winter) and 212 degrees Fahrenheit (summer and maximum engine temperature).

Oils are produced with different viscosities under different climatic conditions. The use of high viscosity oil in winter delays lubrication of the engine until it warms up and during this time the oil will not reach all parts of the engine. Also, the use of low viscosity oil in summer will cause wear of the engine parts. High viscosity in cold weather can also cause the car to start having trouble.

Therefore, choosing the right viscosity for engine oil can be entirely dependent on climatic conditions. With the advancement of science, especially chemistry, by adding polymers to engine oils, production of multi-grade oils (Multi Grade) or multi viscosity, has resolved the need to change the oil in the change of seasons or climatic conditions.

For example, consider two engine oils, 10W-30 and 20W-50:

1. In 10W-30 oil, the number of viscosity in winter is 10 (the letter $\mathrm{W}$ means winter from the beginning of the word winter). Also, viscosity of this product is 30 in summer and when the car engine warms up.

2. In $20 \mathrm{~W}-50$ oil, viscosity is 20 in winter. Also, viscosity of this product is 50 in summer and when the car engine warms up.

This comparison shows that $20 \mathrm{~W}-50$ product has higher viscosity (both in tropical and cold seasons) than $10 \mathrm{~W}-30$ engine oil.

Engine oil suitable for cold regions: For cold regions, it is better to use engine oils that are less condense at low temperatures, or in other words, have lower viscosity so that the car engine is not damaged during the first start on a cold day and is easily started. If viscosity is high, the engine oil may not lubricate well at the first start, causing damage to the engine. Ardabil, Shahrekord, Tabriz, Hamedan, Sanandaj and etc. are among the cities that are better to use low viscosity engine oils. For example, oils 0W-20, 0W-30, 0W-40, 5W-30, 5W-40 and etc. are suitable for these cities.

Engine oil suitable for tropical regions: For cities located in tropical regions of the country, engine oils with high viscosity are suitable. For example, in cities such as Bandar Abbas, Sistan o Baluchestan, Ahvaz, Isfahan, Kerman, and etc., it is better to use engine oils that have high viscosity and/or high concentration at high temperatures. For example, 
50WW, 10W-40, 20W-50, and 15W-50 engine oil are reasonable choices for these cities. Therefore, it is better to pay attention to this important index before buying engine oils.

Engine oil viscosity classification: The first and most important condition of choosing an oil for specific applications is its viscosity. The changes in viscosity of an oil under different conditions have a direct effect on its function. Due to the importance of choosing the right degree of viscosity, different viscosity classifications have been made for various types of engine and industrial oils.

The following are the most important classifications:

1. Viscosity classification for engine oil by the Society of Automotive Engineers (SAE)

2. Viscosity classification for gear oils by SAE

3. ISO viscosity classification for industrial oils

4. Viscosity classification by AGMA for gear oils

In this paper, we are going to discuss SAE j300 and SAE j306 classifications for engine and gear oils, respectively.

Engine oil classification based on viscosity: As mentioned earlier, viscosity is the first and most important feature that should be considered when working with oils. Having suitable viscosity for engine oils under different operating temperature conditions is necessary for proper lubrication of moving engine parts. Oils suitable for use at low temperatures are denoted by the letter W (winter). Oils that do not have the letter $\mathrm{W}$ in their grade are suitable for temperate and tropical weather and for engine operation at normal temperature.

Multi-grade oils are considered non-Newtonian fluids due to the presence of polymer in their formulation, which changes their viscosity as the shear rate changes. Viscosity in this case is called apparent viscosity. The addition of these polymers in turn increases viscosity. In general, the rate of change in apparent viscosity of multi-grade oils is less than that of single-grade oils. As shown in Figure 1, the slope of the viscosity-temperature line for multi-grade oils is lower than for single-grade oils.

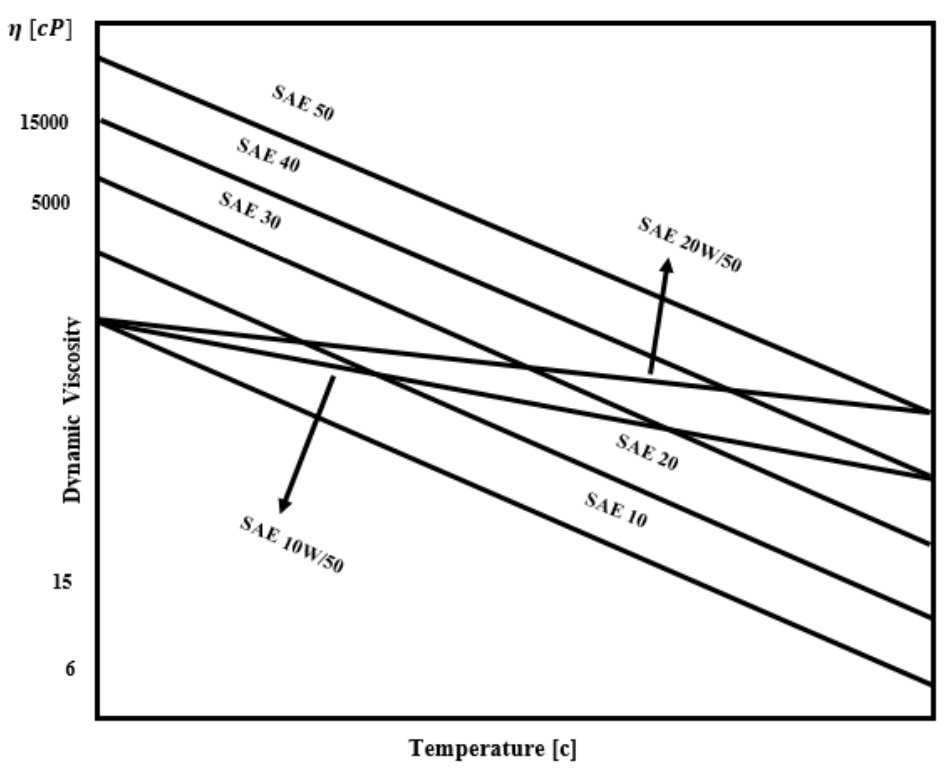

Figure 1: Dynamic viscosity changes with respect to temperature for single-grade and multi-grade oils

Considering viscosity at different temperatures (for example, in cold and at $-20{ }^{\circ} \mathrm{C},-30{ }^{\circ} \mathrm{C}$, and etc., and in heat at $100{ }^{\circ} \mathrm{C}$ ), the Society of Automotive Engineers provides an overview of viscosity for classifying engine oils. Table 1 shows this classification.

In the first column of Table 1, 12 different degrees of SAE for engine oil are given. The degrees that are suitable for cold weather have the letter $\mathrm{W}$ and degrees that do not have $\mathrm{W}$ are suitable for temperate and warm weather. Of course, what temperature each SAE grade is suitable for depends on the engine manufacturer. For example, the proper operating temperatures for different grades of oils in gasoline and diesel engines provided by BMW are shown in Table 2. 
Table 1: SAE classification based on viscosity for engine oils

\begin{tabular}{|c|c|c|c|c|c|}
\hline \multirow[b]{2}{*}{$\begin{array}{c}\text { Degree of } \\
\text { viscosity SAE }\end{array}$} & \multicolumn{2}{|c|}{ Viscosity at low temperatures } & \multicolumn{2}{|c|}{$\begin{array}{c}\text { Viscosity at temperature } \\
\text { of } 100^{\circ} \mathrm{C}(\mathrm{cSt})\end{array}$} & \multirow{2}{*}{$\begin{array}{c}\text { Minimum viscosity at } \\
\text { high shear stress } \\
\text { minimum }\end{array}$} \\
\hline & $\begin{array}{l}\text { Related to } \\
\text { starting the } \\
\text { engine }\end{array}$ & $\begin{array}{l}\text { Related to oil } \\
\text { pumping }\end{array}$ & minimum & maximum & \\
\hline $0 w$ & 6200 at -35 & 60000 at -40 & 3.8 & - & - \\
\hline $5 w$ & 6600 at -30 & 50000 at -35 & 3.8 & - & - \\
\hline $10 \mathrm{w}$ & 7000 at -25 & 60000 at -30 & 4.1 & - & - \\
\hline $15 w$ & 7000 at -20 & 60000 at -25 & 5.6 & - & - \\
\hline $20 w$ & 9500 at -15 & 60000 at -20 & 5.6 & - & - \\
\hline $25 w$ & 13000 at -10 & 60000 at -15 & 9.3 & - & - \\
\hline 20 & & & 5.6 & $<9.3$ & 2.6 \\
\hline 30 & & & 9.3 & $<12.5$ & 2.9 \\
\hline 40 & & & 12.5 & $<16.3$ & $\begin{array}{c}2.9(0 \mathrm{~W} 40,5 \mathrm{~W} 40, \\
10 \mathrm{~W} 40)\end{array}$ \\
\hline 40 & & & 12.5 & $<16.3$ & $\begin{array}{l}3.7(40,15 \mathrm{~W} 40, \\
20 \mathrm{~W} 40,25 \mathrm{~W} 40)\end{array}$ \\
\hline 50 & & & 16.3 & $<21.9$ & 3.7 \\
\hline 60 & & & 21.9 & $<26.1$ & 3.7 \\
\hline
\end{tabular}

In the second column, in front of each of SAE degrees, the maximum viscosity of the oil in terms of centipoise at negative temperatures is listed. In the third column, the maximum viscosity related to pumping oil at low temperatures in terms of centipoise is mentioned. In the second and third columns, the maximum viscosity at low temperature is given only for oils that are suitable for use in cold weather (with W). In the fourth column, the minimum kinematic viscosity at $100{ }^{\circ} \mathrm{C}$ is reported. For example, for $\mathrm{W} 25$ oil, the minimum viscosity at $100{ }^{\circ} \mathrm{C}$ is $9.3 \mathrm{cst}$. If viscosity is less than this value at $100{ }^{\circ} \mathrm{C}$ for such an oil, the oil is too diluted and cannot lubricate properly. For W25 oil, viscosity at $100{ }^{\circ} \mathrm{C}$ does not matter, only this value should not be less than $9.3 \mathrm{cst}$. The fifth column shows the minimum viscosity at high shear stresses at $150{ }^{\circ} \mathrm{C}$.

As shown, at high shear temperature and stress, the minimum viscosity is mentioned only for oils that have high viscosity. In the case of SAE 40 oil, the minimum viscosity is mentioned for two categories of multi-grade oils containing 40 oils.

Gear oil classification based on viscosity: The viscosity of gear oil affects the load-bearing capacity, leakage and noise and determines the ease of movement of the gear. According to Table 3, viscosity at high temperatures (40 and 100 ${ }^{\circ} \mathrm{C}$ ) is related to abrasion, noise and leakage properties of oil, and at low temperatures it is related to investigation of flow properties. 
Table 2: Suitable operating temperatures for multi-grade oils according to BMW standards

\begin{tabular}{c|c|c} 
& $\begin{array}{c}\text { Diesel } \\
\text { engines }\end{array}$ & $\begin{array}{c}\text { Gasoline } \\
\text { engines }\end{array}$ \\
\hline Special oils & \multicolumn{2}{|c}{ Temperature } \\
\hline SAE 20W-50 & {$[0,50]{ }^{\circ} \mathrm{C}$} & {$[-10,50]{ }^{\circ} \mathrm{C}$} \\
\hline SAE 15W-50 & {$[-10,50]{ }^{\circ} \mathrm{C}$} & {$[-20,40]{ }^{\circ} \mathrm{C}$} \\
\hline SAE 15W-40 & {$[-10,40]{ }^{\circ} \mathrm{C}$} & {$[-20,30]{ }^{\circ} \mathrm{C}$} \\
\hline SAE 10W-40 & {$[-20,30]{ }^{\circ} \mathrm{C}$} & {$[-30,20]{ }^{\circ} \mathrm{C}$} \\
\hline SAE 10W-30 & {$[-20,15]{ }^{\circ} \mathrm{C}$} & {$[-30,-10]{ }^{\circ} \mathrm{C}$} \\
\hline SAE 5W-30 & {$[-30,5]{ }^{\circ} \mathrm{C}$} & {$[40,-5]{ }^{\circ} \mathrm{C}$} \\
\hline SAE 5W-20 & {$[-30,0]{ }^{\circ} \mathrm{C}$} & {$[40,-10]{ }^{\circ} \mathrm{C}$}
\end{tabular}

Table 3: Classification of car gear oil according to SAE J306 Classification of oil viscosity of manual transmissions and axles SAE J306

\begin{tabular}{c|c|c|c} 
Degree of viscosity & $\begin{array}{c}\text { Maximum temperature } \\
\left({ }^{\circ} \mathrm{C} \text { for viscosity } 150000 \mathrm{mPa} . \mathrm{s}^{*}\right)\end{array}$ & $\begin{array}{c}\text { Minimum viscosity } \\
\text { at } 100{ }^{\circ} \mathrm{C}(\mathrm{cSt})\end{array}$ & $\begin{array}{c}\text { Maximum viscosity at } \\
100{ }^{\circ} \mathrm{C}(\mathrm{cSt})\end{array}$ \\
\hline $70 \mathrm{w}$ & -55 & 4.1 & - \\
\hline $75 \mathrm{w}$ & -40 & 4.1 & - \\
\hline $80 \mathrm{w}$ & -26 & 7.0 & - \\
\hline $85 \mathrm{w}$ & -12 & 11.0 & 11.0 \\
\hline 80 & - & 7.0 & 13.5 \\
\hline 85 & - & 11.0 & 18.5 \\
\hline 90 & - & 13.5 & 24.0 \\
\hline 110 & - & 18.5 & 32.5 \\
\hline 140 & - & 24.0 & 41.0 \\
\hline 190 & - & 32.5 & -
\end{tabular}

\section{BURNING OIL}

The contents of this section are mainly adapted from some internal publications and conferences, and the systems of reputable and related companies, [6-7]. Oil burn is a problem that often occurs for used and worn out cars. As a result of Burning oil, the oil in the engine is burned and reduced along with gasoline. Usually, due to the burning of engine oil, smoke is emitted from the car exhaust, which may not be visible. The exhaust of modern cars absorbs the smoke from burning oil and prevents it from escaping into the environment.

Identification of burning oil in today's cars: In order to identify burning oil when the car is not smoking, you should check the engine oil gage indicator. If the indicator shows a low level, there is a possibility of burning oil in the engine. Park your car in a clean place for extra security. After 8 hours, move the car. If there is no oil stain under the car, the possibility of burning oil is very high, but if there are oil stains, your car engine has a leak or hole that should be repaired as soon as possible.

Of course, there are other ways to identify burning oil as follows:

1. The head of the candles is greasy

2. The smell of burning oil in the engine compartment and car hood 
3. The inside of the exhaust pipe is greasy and oily

4.Use instrumentation to identify burning oil such as compressor gauge

Causes of the engine burning oil:

If oil enters combustion chamber, it burns and the resulting smoke moves to exhaust. Regarding the location of combustion chamber, it can be mentioned that there is a space in the engine called combustion chamber in which combustion of gasoline (diesel) takes place.

The reasons for oil entering combustion chamber are as follows:

1. Wear of piston ring and cylinder walls

2. Break one or more piston rings

3. Corrosion of the cylinder or piston wall

4. Damage to cylinder head gasket and crankshaft

5. Gate rubber wear

6. Crush radial shaft seals

7. Damage to bearings and connecting rods

8. Severe valve gate friction and the like

Today's cars are designed to burn as little oil as possible.

Reduce engine burning oil: The chemical additives can be used for this purpose. This additive is cheaper and lighter than engine oil. As a result, we can use this additive and measure the amount of oil when the oil is reduced. Because it is lighter, it is placed on top of the oil and moves towards combustion chamber. Of course, proper engine oil also helps reduce burning oil to some extent.

Burning oil problems: Burning oil reduces engine power and fuel efficiency and is extremely harmful to the environment.

Types of smoke coming out of car engines: If smoke comes out of exhaust, be sure to think about treating your car engine. Smoke does not always mean burning oil, and the color of the smoke can indicate the type of problem the car has.

1) Blue engine smoke

Blue means burning oil in the car engine.

Solution: Test piston compress and keep the oil level balanced

2. White smoke coming out of the engine

White smoke means that the liquid in the radiator burns and evaporates in combustion chamber. The liquid in the radiator, which also includes anti-freeze, burns like oil when it burns. Refer to a qualified mechanic to prevent severe damage to valves, cylinders and seals.

Solution: Keep the car engine cool and consult a car mechanic and specialist.

3. Black engine smoke

This color is due to excessive burning of gasoline in gasoline vehicles. Fuel system defects, malfunction of injector and oxygen sensor and filter clogging are the most important causes of black smoke.

Solution: If your car uses throttles, lower it. Use a suitable air filter and replace the oxygen sensor if necessary.

\section{PLANT-BASED ENGINE OILS}

The contents of this section are mainly adapted from some national conferences, and the systems of reputable and related companies, [8-9].

One of the great challenges of the industrial world today in all countries of the world is the growing energy crisis that is rapidly causing all the economic, cultural and social balances of different countries undergoing unpredictable changes. The shortage, gradual decline and non-renewable nature of fossil fuels in the field of energy supply led scientists in various fields of science to seek practical solutions to overcome the problems and consequences of the energy crisis in various fields. 
The strategic issues and sharp fluctuations in the global market of fossil fuels on the one hand, and growing steps to reduce environmental pollutants on the other hand, including the strong driving forces led policymakers in industrialized countries moving to renewable energy sources such as water, wind, geothermal, biomass, solar and hydrogen. Biodiesel, which is one of the biomass sources, according to energy experts, consistent with bioethanol, is one of the pioneers of alternative technologies for oil resources in order to counteract the increase in energy demand and reduce environmental pollution caused by combustion engines available. Biodiesel, which is actually a mono-alcohol ester of plant-based oils and animal fats, is the best alternative to diesel fuels in diesel engines.

Apart from advantages that these oils have for environmental protection, they can generally be expected to have lower viscosity, non-toxicity, better lubrication, and less fouling than petroleum-based oils. With increasing interest in degradable lubricants and environmental concerns about the fate of unrefined oils, the lubricant industry has shifted to the use of plant-based oils. These oils have added more value to the lubricant industry, because they can be formulated with simple materials such as mono and polyesters supplied from farmland and even animal fats.

In the past, polyesters were used in other industries due to its non-toxicity and degradability, and caused less carbon to be released in the production process. But now these materials are used to manufacture base oils, and today it is easy to make a complex compound for lubrication from mono esters, which of course are efficient under different temperature conditions.

Application of plant-based oils from the past until now:

First, plant-based oils were processed from castor oil and used for racing cars. The main disadvantage of these oils was their short life, which made them greasy in a short time, but the excellent viscosity properties of these oils, in addition to their low cost of supply, made them an extremely suitable option for these cars.

Of course, in the case of racing held 24 hours a day or endurance, the oil after a few rounds of the race should be changed, because the half-life of these oils until greasing is about 2 to 3 thousand kilometers. But today, with changing the formulation of plant-based oils, these oils can last as long as industrial base oils and are even a good choice for new thrusters because they can be processed at lower viscosities.

In 2013, the USDA set a standard according to which oils that used up to $25 \%$ of plant-based oils could be referred to as biodegradable oils. Currently, following this rule, IRANOL Oil Company offers Tetra series liquid oil in the Iranian market with a viscosity of 10W-40 and API level of SL, in which 35 to $40 \%$ of degradable plant-based oils are used.

Plant-based oils and their use:

The use of European plant-based oils is estimated at 100,000 tons per year, which covers a large part of lubricants on the market in this country. Of course, these lubricants are not only used for car engines, but also a large volume of these oils are used in high-risk industries such as railways and hydraulic systems. However, this volume will increase in the coming decades because environmental laws become more stringent in the coming years and companies will be forced to use these types of lubricants to reduce the amount of non-degradable waste.

Also, the use of these oils will increase where there is high sensitivity to the environment. EU countries, for example, are required to meet high standards to reduce their damage to the environment, and it seems that the use of plant-based oils is a good option.

Of course, separate standards should be set for plant-based oils. For this purpose, in 2016, European Committee for Standardization (CEN) defined a special standard for these lubricants for the European Union called EN 16807. Of course, this standard investigates the most basic requirements for determining the quality of plant-based oils for their degree of degradability in the environment, toxicity and technical strength.

Advantages and disadvantages of plant-based oils: Apart from advantages that these oils have for protecting the environment, they can generally be expected to have lower viscosity, non-toxicity, better lubrication, and less fouling than petroleum-based oils. But advanced versions of these oils are highly dependent on their formulation. With controlling the formulation, these oils can delay oxidation process and have greater stability against heat generated by the engine function.

The most important disadvantages of first generation plant-based oils are their short shelf life and low heat resistance. But with a slight change in the formulation of these oils, the scientists can increase the distance that can be traveled with these oils from 2,000 kilometers to about 10,000 kilometers; as what we expect from petroleum-based oils.

Therefore, with the changes made, plant-based oils in this respect are not much different from petroleum-based oils that are processed from group one to three base oils. However, their use in engines that use natural fuels such as biodiesel, causes chemical reactions between these two substances, which is called FAME.

This problem occurs at the microscopic level and is due to the natural properties of lubricants and natural or biological fuels. Therefore, the use of plant-based oils in thrusters that use biodiesel fuel is not recommended worldwide. 
Plant-based engine oils and microbes: Due to the chemical reactions that take place between biodiesel fuel and plantbased oils and degradability of these oils by microbes in nature, it is thought that the same microbes can grow inside the engine, while modern plant-based engine oils that are common today use only a percentage of plant-based oil, and the rest of their base oil is petroleum and acts as a toxin for the growth of bacteria. Also, additives added to these oils do not allow the activity of bacteria.

In addition, penetration of smoke and metals into the lubricant solution and the flow of this oil in different directions during engine operation is another factor that does not allow the activity and growth of bacteria in the engine. In addition, one of the needs of bacteria to maintain their survival is the presence of water and moisture in the space, while the space inside the engine is very dry and at a very high temperature.

Plant-based oils replacing synthetics: Finally, it should be noted that due to the increasing market demand for hightech and low-viscosity engine oils, plant-based oils can be considered as a suitable alternative to full-synthetic bases, because these base oils in addition to having low viscosity, can be produced domestically, and IRANOL Oil Company has been able to achieve the ability to manufacture these oils. Even recently, Castrol has been producing $5 \mathrm{~W}-30$ engine oil with API SN standard using plant-based oil; an action that indicates that plant-based oils can become a suitable alternative to advanced full-synthetic bases, the production of which is monopolized by only a few countries and are not willing to transfer technology to Iran. Therefore, if these plans are supported, there is a possibility of industrial internalization of these base oils and they can be mentioned as the savior of Iran's lubrication industry.

Practical activities to reduce engine oil and fuel impurity: American Society for Testing and Materials (ASTM) is developing a new standard for testing the presence of metals in crude oil. This standard brings a new level of quality to all petrochemical products, from fuels to lubricants and other petroleum condensates. This new standard (hereinafter referred to as ASTM D8322) describes an experimental method for microwave plasma atomic emission spectroscopy (MP-AES) that can identify the presence of metallic elements such as nickel, vanadium, iron and many other metals in crude oil and other heavy fuels.

"These metals are usually found in crude oil," said George Gonzalez, a member of the International Institute; But it can be problematic for downstream industries and refineries in this sector. "This standard can be particularly effective for 700 refineries worldwide and our contracted laboratories that investigate crude oil samples on a daily basis."

According to Gonzalez, the new standard will be profitable by providing safer tools for element analysis in the industry; because the presence of different elements does not require expensive gases, acetylene and argon. In addition, sampling method for this experiment does not require digestion of the sample by acidic methods or the use of sample ash; because in MP-AES method, the prototype does not require special operations for identification.

Digestion should be described as a method used to prepare a sample of acid to decompose elements. Ash use is another method in which Bunsen burner is used for decomposition to divide the sample into carbon and primary elements. However, in both methods of digestion and ash use, a lot of time is spent to complete the sample preparation process and are generally considered to be dangerous in nature.

"This standard makes the industry receptive to new technology, and in the future we will have a high demand for this standardized technique," finally Gonzalez concluded.

Due to the more advanced oil of engines in the future and the need for the most advanced lubricants due to the alloys in thrusting parts, it seems that in the future the use of this method to identify the presence of metals will be more accepted and in addition to crude oil included in lubricants and even engine oils.

\section{CONCLUSION}

The types of engine oils were introduced and advantages of each over the other were investigated. A suitable engine oil for the car and its reasons were discussed. The engine oil viscosity was discussed. The engine oils suitable for cold and tropical regions of the country were introduced. The standard classification of engine and gear oils in terms of viscosity was also discussed. Burning oil, its causes, methods of identification and reduction were described. Plant-based engine oils, their applications, advantages and disadvantages, and complementary environmental issues were discussed.

\section{REFERENCES}

[1] A. R. Masoudi, Z. Kouhi, "Four Seasons Engine Oils and General Evaluation of These Oils in the Iranian Market (In Persian)", 2th Condition Monitoring \& Fault Diagnosis Conference, Tehran, Iran, February 24-25, CMFD02_038., 2008.

[2] I. Arefian, H. Asady, M. R. Monazam Esmaeilpour, Z. Zolghadr, Y. Zarif, "Investigating Impact of Motor Oil Quality on Vehicles Engine Induced Noise Level (In Persian)", Journal of Health and Safety at Work, vol. 5, no. 3, pp. 21-28, 2015. 
[3] R. Hesampour, M. Hasani, K. Heidarbeigi, "Evaluation of Oil Viscosity Behavior in Different Engine Functions (In Persian)", 2th National Conference on Mechanization and New Technologies in Agriculture, Ahvaz, Iran, May 11 12, NCAMNT02_078, 2016.

[4] J. G. Wills, "Lubrication Fundamentals", M. Dekker, 1980.

[5] D. M. Pirro, M. Webster, E. Daschner, "Lubrication Fundamentals, Revised and Expanded", CRC Press, 2017.

[6] S. Mohajeri, B. Espidkar, F. Harsaj, "Investigation of Fuel Consumption Reduction in Vehicles Using Fuzzy MultiCriteria Decision Making Approaches (In Persian)", Journal of Science and Engineering Elites, vol. 3, no. 5, pp. 5057, 2018.

[7] H. Roshan Ravesh, H. Sadrnia, M. Khojastehpour, "Ensurement of Accuracy of New Engine Oil before Use through Oil Analysis (In Persian)", 4th National Conference on Mechanical and Electrical Engineering Science and Technology of Iran, Tehran, Iran, March 11, DMECONF04_013, 2019.

[8] H. R. Eskandari, R. Tavasoli, "Effect of Vegetable Engine Oil on Reducing Fuel Consumption and Environmental Hazards (In Persian)", National Conference Celebrating Successful Managers in the Year of Resistance Economy, Action and Practice, Tehran, Iran, February 16, EMOGHAVEMAT01_004, 2017.

[9] S. Salmani, S. S. Ashraf Talesh, "Review of Biodiesel Production Processes and Study of Effective Parameters (In Persian)", 5th National Conference on New Research in Chemistry and Chemical Engineering, Tehran Iran, January 24, IRCCE05_077, 2019. 